\title{
Implementing Flexible Systems in Doctoral Viva Defense Through Virtual Mechanism
}

\author{
Valliappan Raju' ${ }^{1}$ (B)
}

Received: 30 November 2020/Accepted: 11 February 2021/Published online: 21 March 2021

(C) Global Institute of Flexible Systems Management 2021

\begin{abstract}
Year 2020 has cultivated new arena in education. Covid-19 has not only reformed the world but also revived the process of operations. One among them is academics. Never in history of education was a lecture delivered without the physical presence of lecturers, in an academic environment. Even in present wildest innovative decade, the idea of eliminating the academia was not an option. However, after the pandemic encounter, it happened. These are not mere changes, but it is a transformation. While this phenomenon is getting acceptable gradually by takers, the mammoth turnaround is happening in Ph.D. final viva voce defenses too. Practice of online defense is approved by leading Universities so as to avoid stagnation of researchers in final stage. Question is, will it be appropriate to accept final defenses in online stream? and has the institutions developed rubrics to assess the researches which are presented online? Finally, if this is the only choice then how best we can use the technology to generalize it as a system? This research was executed through Delphi technique method from academia, research aspirants and policy-makers. Partial least square is used to quantify the data after interpreting qualitative data. Thirteen homogeneous University's respondents were used as sample. Focus of this paper remains to substantiate the benefits of emerging technology and developing a scheme for virtual streaming, rather identifying reasons to avoid them.
\end{abstract}

Valliappan Raju

valliappan008@gmail.com

1 Limkokwing University of Creative Technology, Cyberjaya, Malaysia
Keywords Flexible systems · Research - Technology · Virtual mode · Viva

\section{Introduction and Background}

Online-mode is the talk of 2020. Business operations have gone predominantly in virtual mode. No industry is exceptional in this. Rather than the debate of whether it is worth or irrelevant, the mindful point to be noted is, do we have a choice? Online-operation abets to connect people who are geographically disconnected. But now, it is beyond that. People are rigorously forced to articulate this medium (Chetty \& Phung, 2018). Higher education institutions (HEIs) have taken a big blow. University of Cambridge announced that for further 18 months w.e.f. May 2020, they shall be delivering the classes through electronic-mode (Agrawal et al., 2016). Nevertheless, onlineeducation has been in practice for long period. It was not forced, but seen as supplement to lecturers (Sushil, 2016). Off late the growth of online-education has been one among four important key trends due to the changing landscape of higher education industry across the globe. A report claims that even students want empowerment so bypass and surpass the conventional journey or routine (Law et al., 2020). Having mentioned this, there is a claim that HEIs are becoming imperatively globalized by offering their programs across the world with an objective to unite the students from multi-diversified cultural meadow (Popescu et al., 2000). The phenomenon of quality-delivery and multi-diversity is two vital components of growth. These have to be nurtured by certain innovative solutions. In a way, it is the online-mode for education.

This research is executed based on data collected from higher educational institutions (HEIs) who have 
volunteered to implement the flexible system (Sushil, 1997) of virtual defense in doctoral viva assessment. Ph.D. degree is considered as final formal learning in an academic environment. In the year 1917, Ph.D. degree got introduced to researchers with the parallel lines of the USA and Germany model. It quickly became widespread and popular with both UK and international students (Simpson \& Renate, 1983). Though Post-doctorate is similar to doctorate study, it is more of an employment offered by the institution to the researchers. It is well known that a researcher has to defend his or her thesis to the research panel successfully to acquire the degree of doctorate (Bhaumik et al., 2019). This process may differ to studies in hardcore science and social science. The focus is laid on social science researches, and thus, the practice of defense is essential to attain the award. Be it top tier institution or community-based institution, as long as they offer research degree, the practice of defense is mandatory in final stage. This practice has never been changed since inception until early 2020 (Rao \& Wadhwa, 2002). That is, since 1917 until 2020 the defense system has been in motion untouched for whatsoever reason. There are events like closedviva, open-viva, public-viva, presentations that happen in virtual platforms. Is it worth or worthless to conduct viva through virtual mode? The main questions will be answered following sections will attempt to analyze through this research.

\section{Problem Statement}

Philosophy of tangibility is getting missed while assessing the researcher's defense in online-mode and importantly the conspiracy of plagiarizing the defense becomes a threat in future if online defenses are continued. However, as a part of migrating to technological revolutions, it is necessary to expedite a method to accept this flexibility (Abbott \& Banerji, 2003; Shukla et al., 2019; Evans \& Bahrami, 2020) in virtual system of defense and at same time identify an appropriate rubrics scale to assess the defense. This research article is submitted with the intention to develop a flexible virtual system in terms of rubrics that accommodates the thirst of researcher and also boosts the ethics of defense practices.

Based on existing studies from 2014 until 2020, it was understood that defense practice is considered as highly conventional even after several revolutions in educational pedagogy (Hwang et al., 2020).

It is evident that all sectors are transforming to digital mode, be it entertainment or healthcare or any serviceoriented industry. Education plays a dominant role in services which around $53 \%$ to $54.2 \%$ is captured in form of professional education, higher education, vocational education and school education. During twentieth century, there were several inventions than discoveries; however, in present era, there are more discoveries than inventions. This enabled digital method to intrude in services sector as an extension of technology-development since 2000 (Hashim Alkipsy et al., 2020). From there the leap taken by technology has been a revolution. Education sector was like less exploited by this revolution. For instance, the students and teachers were existing in the conventional format to seek and deliver services while evolving for strategic management in academic institutions (Sushil, 2016). E-learning was implemented as a supplement to institutions, which also builds a flexibility in ecosystem (Sushil, 2015). The students were forced to get accommodate for e-learning, because of wide spreading glory. Concerns like technological knowledge, adequate equipment, internet services, etc., were not complete in full. Still, as a forceful growth, e-learning (Acharya, 2019) was packed in education institutions and made to look like mandatory. There are benefits of this learning but there were also more issues. Adding to the flame, the present covid-19 pandemic has worsened the scenario (Poh Phung et al., 2019).

The above statement needs not go through arduous investigation to gauge its substance. Technology as a tool has given massive leaps in livelihood, at the same time there has been loads of evidences of singularities. Introducing automatic maneuver in Boing 737 max caused the tragedy of causalities in Ethiopian Airlines in 2019. Blaming the technology or praising it has been for long time. The ground point one needs to understand is that the technological growth cannot be un-rooted once they are plowed in. It is the duty of everyone or at least to researchers to find optimum methods to overcome the deteriorating effects. The other point is that HEIs is unaffordable to send out unskilled and incompetent researchers to world (Piansoongnern, 2013). Thus, the objective is to live with this online-mode, but there is tremendous need to construct a guideline before any further downturn.

For instance, e-learning could have been a good gamechanger in higher education. But it was suppressed with limitations and singularity. Since its motive was not measured and demonstrated people took it for granted and later started complaining on its utility. There could have been a clear protocol on its usage, licensing and implementation. This being missed, the entire idea of e-learning got faded. Though there are numerous companies across the globe selling e-learning services, there has not been a wave. It is the duty of academia and researchers to avoid another setback to happen. For this purpose, before virtual system gets out of hand in academia, this research is been conducted to submit appropriate standards for it. 
1. To comprehend the role of emerging virtual system to work at doctoral viva

2. To propose a resilient system to achieve best defense practice in final stage

The non-technological assessments are based on five elements such as knowledge, ability, communication, perseverance and skills (Sharma et al., 2010). These may interrelate among them in certain area, namely communication and skills look similar. Unless these differences are well understood, then it would be cumbersome to assess. However, the research aim is to replace this with a persuasive measurement model while defending through virtual system so that misappropriations and malpractices can be avoided. Below Table 1 is been developed and these kinds of tables abet the assessor to evaluate the candidate. Before discussing about new model, it is essential to witness the existing rubrics that are followed by HEIs. Though the below table is created by the author, the rubrics in general are almost similar.

\section{The Literature on Virtual Systems}

Virtualization of systems is moving from minority segment to flagship utilities and their implementation is increasing upwardly (O'Connor, 2004). This research of Connor conveys that the race to march equivalent to virtual technology. To prove this, if virtual trends are noticed both

Table 1 Rubrics for assessing final defense viva. Source: Author self-created

\begin{tabular}{|c|c|c|c|c|c|}
\hline $\begin{array}{l}\text { Stream } \\
\text { Standards }\end{array}$ & $\begin{array}{l}\text { (1) } \\
\text { Highly } \\
\text { accepted }\end{array}$ & $\begin{array}{l}(2) \\
\text { Accepted }\end{array}$ & $\begin{array}{l}\text { (3) } \\
\text { Accepted with } \\
\text { correction/ } \\
\text { modifications }\end{array}$ & $\begin{array}{l}\text { (4) } \\
\text { Not } \\
\text { satisfactory }\end{array}$ & $\begin{array}{l}(5) \\
\text { Reject }\end{array}$ \\
\hline $\begin{array}{l}\text { Researcher possesses ability to demonstrate the problem } \\
\text { statement clearly and legitimately }\end{array}$ & $\begin{array}{l}\text { Shows an } \\
\text { Excellent } \\
\text { ability } \\
\text { describes } \\
\text { Research } \\
\text { problem }\end{array}$ & $\begin{array}{l}\text { Shows a good } \\
\text { Ability to } \\
\text { describe } \\
\text { Research } \\
\text { problem }\end{array}$ & $\begin{array}{l}\text { Exhibits a fair } \\
\text { Ability } \\
\text { describe } \\
\text { research } \\
\text { Problem }\end{array}$ & $\begin{array}{l}\text { Exhibits little } \\
\text { Ability to } \\
\text { describe } \\
\text { Research } \\
\text { problem }\end{array}$ & $\begin{array}{l}\text { Exhibits nil } \\
\text { Ability to } \\
\text { describe } \\
\text { Research } \\
\text { problem }\end{array}$ \\
\hline $\begin{array}{l}\text { Researcher possesses ability to integrate } \\
\text { The Relevant literature and able to illustrate theory }\end{array}$ & $\begin{array}{l}\text { Exhibits an } \\
\text { Excellent } \\
\text { understanding } \\
\text { Of relevant } \\
\text { literature }\end{array}$ & $\begin{array}{l}\text { Possesses a } \\
\text { good } \\
\text { Understanding } \\
\text { of relevant } \\
\text { Literature }\end{array}$ & $\begin{array}{l}\text { Possesses a fair } \\
\text { Understanding } \\
\text { of relevant } \\
\text { Literature }\end{array}$ & $\begin{array}{l}\text { Possesses little } \\
\text { Understanding } \\
\text { of relevant } \\
\text { Literature }\end{array}$ & $\begin{array}{l}\text { Possesses nil } \\
\text { Understanding } \\
\text { of relevant } \\
\text { Literature }\end{array}$ \\
\hline $\begin{array}{l}\text { Researcher possesses knowledge of research Strategies } \\
\text { and methods eloquently }\end{array}$ & $\begin{array}{l}\text { Reveals an } \\
\text { Excellent } \\
\text { knowledge of } \\
\text { Research and } \\
\text { methods }\end{array}$ & $\begin{array}{l}\text { Possesses a } \\
\text { good } \\
\text { Knowledge of } \\
\text { research } \\
\text { and methods }\end{array}$ & $\begin{array}{l}\text { Possesses a fair } \\
\text { Knowledge of } \\
\text { research } \\
\text { and methods }\end{array}$ & $\begin{array}{l}\text { Possesses little } \\
\text { Knowledge of } \\
\text { research } \\
\text { and methods }\end{array}$ & $\begin{array}{l}\text { Possesses nil } \\
\text { Knowledge of } \\
\text { research } \\
\text { And methods }\end{array}$ \\
\hline $\begin{array}{l}\text { Researcher exhibits the ability to present orally the } \\
\text { problem statement, research objectives, research } \\
\text { approaches and plan for thesis construction }\end{array}$ & $\begin{array}{l}\text { Exhibits an } \\
\text { Excellent } \\
\text { ability to } \\
\text { Present orally } \\
\text { the } \\
\text { Proposed } \\
\text { dissertation } \\
\text { Research }\end{array}$ & $\begin{array}{l}\text { Exhibits a } \\
\text { good } \\
\text { Ability to } \\
\text { present orally } \\
\text { The proposed } \\
\text { dissertation } \\
\text { Research }\end{array}$ & $\begin{array}{l}\text { Exhibits s a } \\
\text { fair } \\
\text { Ability to } \\
\text { present orally } \\
\text { The proposed } \\
\text { dissertation } \\
\text { Research }\end{array}$ & $\begin{array}{l}\text { Exhibits little } \\
\text { Ability to } \\
\text { present orally } \\
\text { The proposed } \\
\text { dissertation } \\
\text { Research }\end{array}$ & $\begin{array}{l}\text { Exhibits nil } \\
\text { Ability to } \\
\text { present orally } \\
\text { The proposed } \\
\text { dissertation } \\
\text { Research }\end{array}$ \\
\hline $\begin{array}{l}\text { Researcher demonstrates skills to respond to } \\
\text { Questions and able to defend the Thesis expressively }\end{array}$ & $\begin{array}{l}\text { Exhibits } \\
\text { excellent } \\
\text { Ability to } \\
\text { respond to } \\
\text { Questions } \\
\text { about } \\
\text { proposed } \\
\text { Dissertation } \\
\text { research }\end{array}$ & $\begin{array}{l}\text { Proves good } \\
\text { Ability to } \\
\text { respond to } \\
\text { Questions } \\
\text { about } \\
\text { proposed } \\
\text { Dissertation } \\
\text { research }\end{array}$ & $\begin{array}{l}\text { Demonstrates } \\
\text { fair ability } \\
\text { To respond to } \\
\text { questions } \\
\text { About } \\
\text { proposed } \\
\text { Dissertation } \\
\text { research }\end{array}$ & $\begin{array}{l}\text { Proves little } \\
\text { Ability to } \\
\text { respond to } \\
\text { Questions } \\
\text { about } \\
\text { proposed } \\
\text { Dissertation } \\
\text { research }\end{array}$ & $\begin{array}{l}\text { Proves nil } \\
\text { Ability to } \\
\text { respond to } \\
\text { Questions } \\
\text { about } \\
\text { proposed } \\
\text { Dissertation } \\
\text { research }\end{array}$ \\
\hline
\end{tabular}


AMD and Intel have shifted from escalating the analog speed of processors (Pinsky et al., 2020). According to Wagner et al. (2001), the information of virtualization in an organization can assemble a single view, or of a client or a profile by clubbing together all the information by storing it in various repositories (Farooq \& Raju, 2019). To make the work place completely virtual is the future and it is a strategic development (Sushil, 2016). Few leading virtual system services providers are thriving toward the phenomenon called virtual nirvana, and almost all companies are footing their first step because of lack-in-choice and through their present mobilization of virtual projects (Raju \& Phung, 2020). The next expected in basket is more of virtual server system configuration, and then to integrate the process of virtualization across storage, servers and its network (Chetty \& Phung, 2018). And (Raju \& Tamjis, 2018.) indicates that there is significant transformation in virtualization process in the past decade (2010-2020) which serves as the key to this research. However, other scholars submit their inquiry of future with the technology, specifically in the area of education (Kolt, 2009). Data being the king of these kinds of research, entire flexibility system's big data analytics articles were reviewed. Particularly from (Grover \& Kar, 2017; Hanafizadeh \& Nik, 2020) who insisted that education institutional researches on flexibility systems should have big data spectrum in it. According to ancient system of practice, all oral defense in Universities was done face-to-face, however, the administrators attempted to review new mode for conducting this and eventually failed (Bernoulli, 1954). This literature is still valid as it was retrieved from FT50 journal Econometrica from the year 1954. These give more validation that since many years there has been a discussion of revamping this system in higher education. Innovation is a part of growth in every sector (Harvard Business Review Staff, 2016). Unless there is prominent innovation, a concept or a product or mechanism or industry or system cannot change. If innovative practices are injected in present traditional systems, then there are probabilities of rapid growth without the concern of 'ceteris paribus', i.e., external factors remain same as before ( $\mathrm{Hu}$ et al., 2016).

\section{Conceptual Framework}

Following research framework in Fig. 1 has been constructed for the purpose of this study. While there are four independent variables (constructs), a mediating variable, viz. online platforms have been included to check the significance with assessment rubrics and research defense. The dependent variable is about virtual defense system in whole, as this is the primary outcome or agenda of this research study.

\section{Research Hypothesis}

There are three direct testing, two indirect testing and one mediator testing proposed in this study. This is developed based on Baron and Kenny model of mediation analysis (Hmedan et al., 2018). Following are hypothesis statements (Figs. 2, 3).

$\mathrm{H}_{1}$ Technology has a significant impact on virtual defense.

Since technological tools/platforms are used in virtual defense, it was vital to test the relationship between technology and virtual defense. It is been hypothesized for the purpose of highlighting the importance of technology.

$\mathrm{H}_{2}$ Assessment rubrics have a significant impact on virtual defense.

Assessment is a key factor for arriving results. Thus, rubrics for defense have been proposed in this research. It has been hypothesized for the purpose of highlighting the importance assessment methods.

$\mathrm{H}_{3}$ Interpersonal skills have a significant impact on virtual defense.

Executive communication is one of the factors to be vetted during defense. There are probabilities that candidates get rid of this by being seated or be static station. Hence, all interpersonal skills have to be investigated.

$\mathrm{H}_{4} \quad$ Assessment rubrics have significant impact on virtual defense through the mediating role of online platforms.

For the purpose of testing the role of online platforms such as Zoom, WebEx, Google Meet, and Adobe Connect, this hypothesis is been tested. While online platforms cannot be as independent variable, the author has attempted to test it as mediator.

$\mathrm{H}_{5}$ Research defense has a significant impact on virtual defense through the mediating role of online platforms.

If this hypothesis is insignificant, it would be less cumbersome to arrive that online platforms do not mediate in full. It is because; this testing is to strengthen the role of mediator.

$\mathrm{H}_{6}$ Online platforms mediate between assessment rubrics, research defense and virtual defense.

This is a contra testing for Hypothesis $\left(\mathrm{H}_{5}\right.$ and $\left.\mathrm{H}_{6}\right)$. It enables to understand whether online platforms mediates in full or in partial. Structural equation modeling (SEM) will be done to test it. 
Fig. 1 Conceptual framework. Source: Self-Constructed Framework by Author

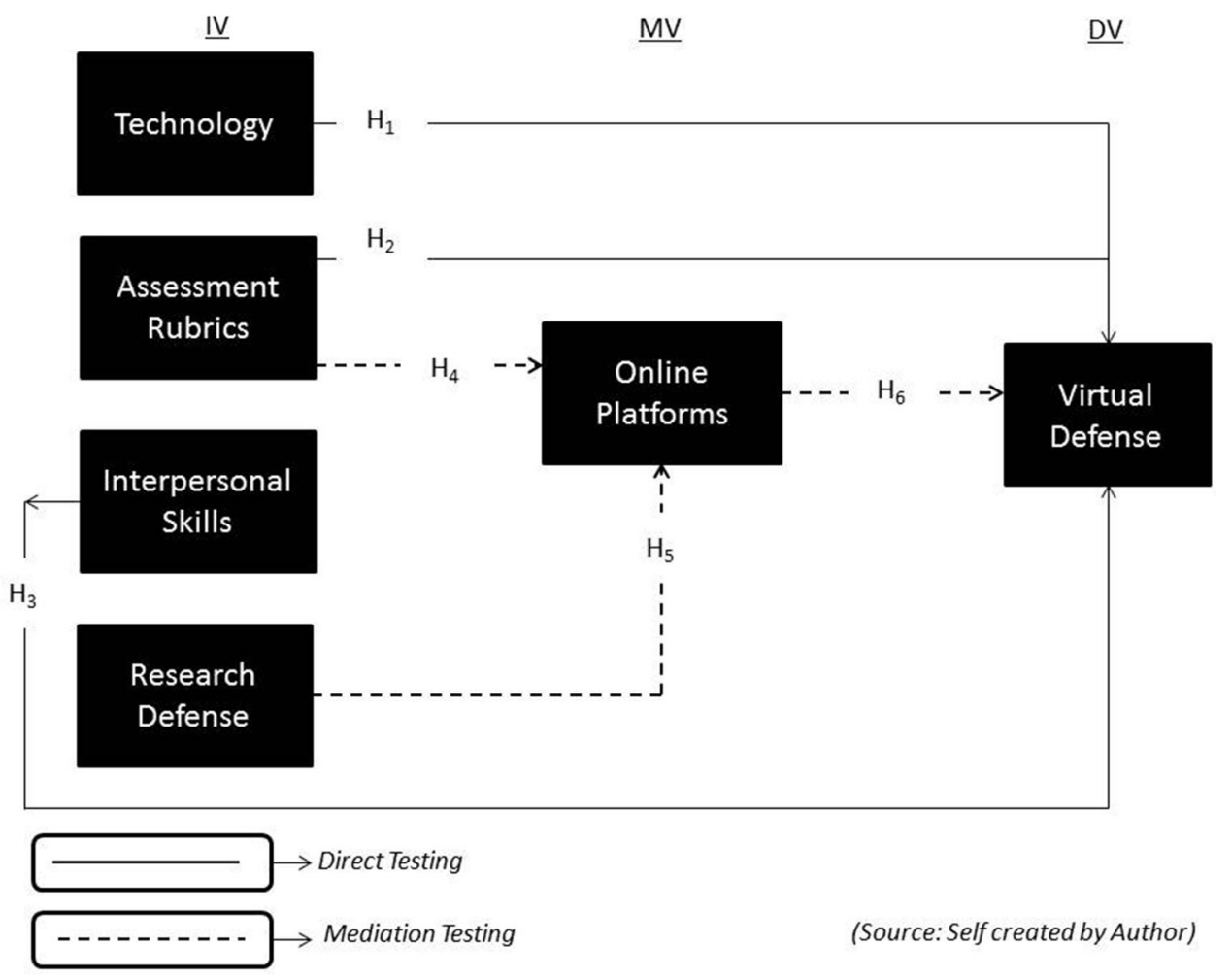

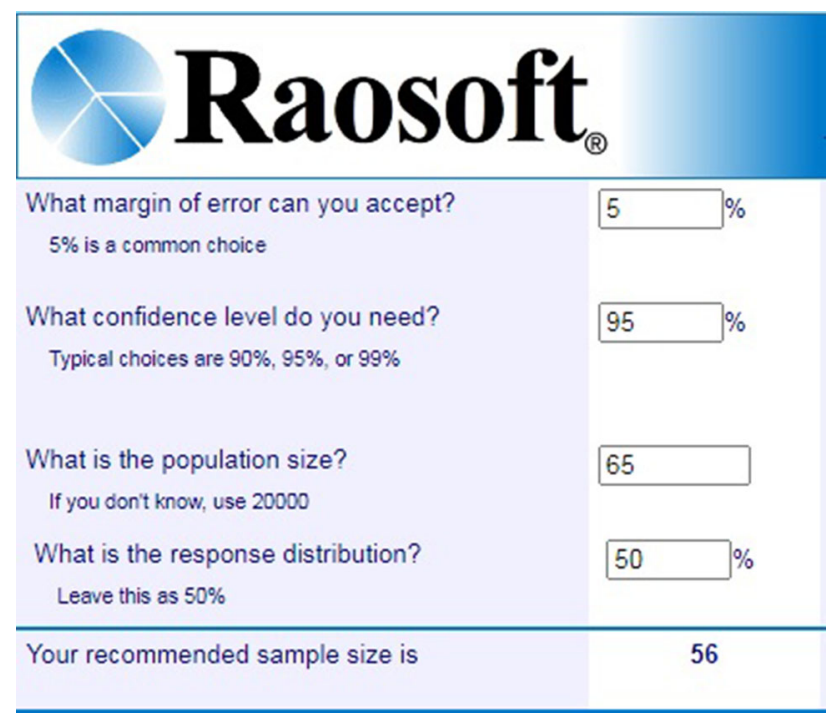

Fig. 2 Sample size calculator. Source: Sample Size Calculation through Raosoft by Author

\section{Discussion on Hypothesis Development}

The above hypotheses were developed further to the construction of conceptual framework. Technology, assessment rubrics, interpersonal skills, research defense were considered as exogenous constructs, i.e., independent variables for this study. These were retrieved from existing studies pertaining to implementation of flexible mechanism. The first three variables were made to identify the relationship with virtual defense. 'Research defense' alone was not tested directly but with the mediator called 'online defense.' Ultimately, these claims were hypothesized and tested accordingly (Tables 2, 3).

\section{Research Methodology}

This research is done with Delphi technique where the process of data collection is done after questioning at group consensus by observing the respondents along with rounds of questionnaires and also recording the group response before each question. According to (Alexandra \& Gordon, 2020), this technique is most suitable for technological studies. This kind of research boasts importance in academia, and thus, it would be appropriate to include views, opinions, ranking of factors, etc., for arriving a solution. Hence, Delphi technique was used. As quoted by Alexandra above, for technological studies, the most suitable method is mixed-method mode. Among this, Delphi technique stands tall.

A mini-pilot study was done with 12 respondents in Malaysia, whereby it was critical to evaluate the data because the responses were overlapping 89-93\% unanimously. In an academic research, this kind of lower-sample is highly discouraged; however, for the sake of pilot study, this was done. This also made the author to understand that 


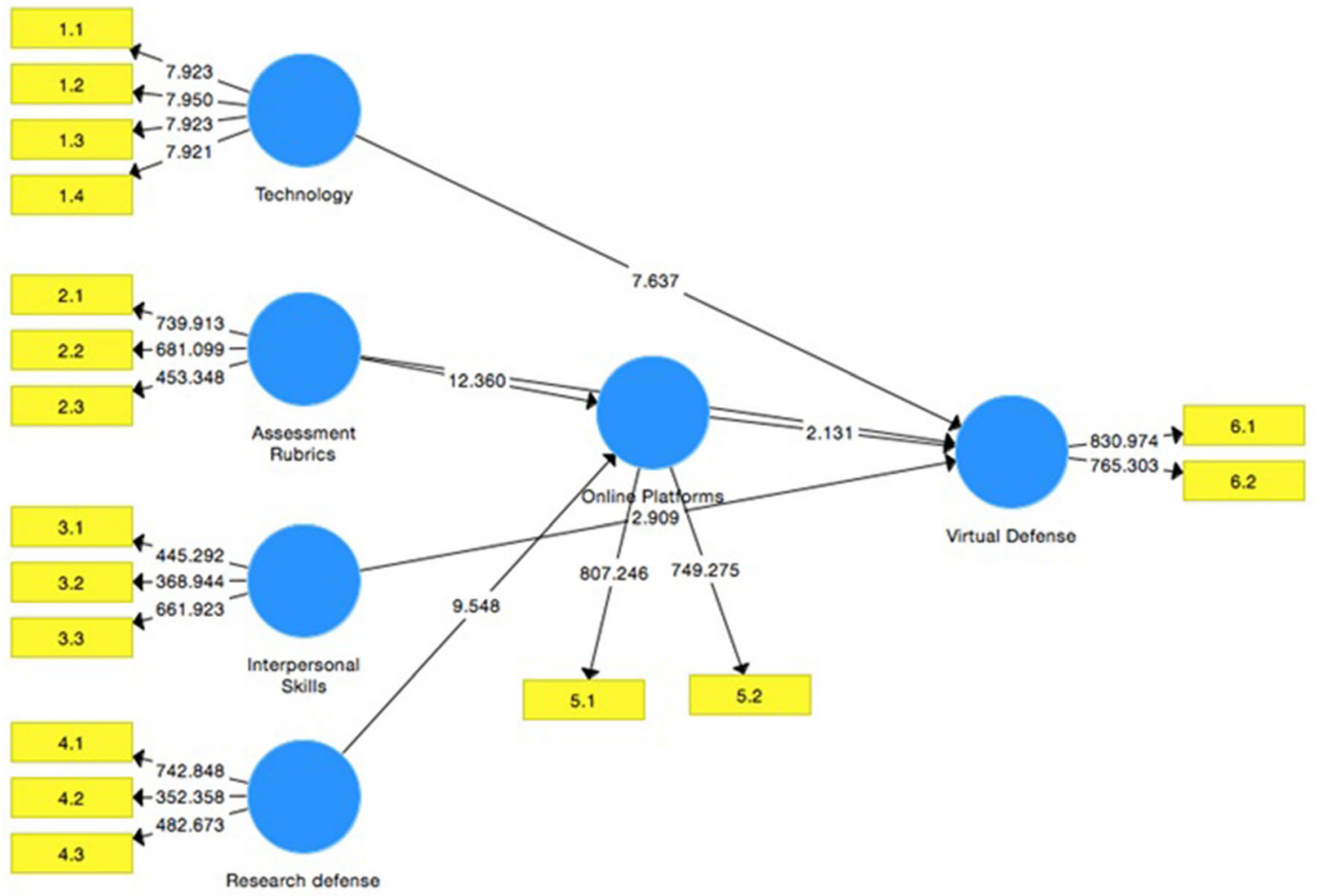

Fig. 3 Path coefficient model

Table 2 Target nations for HEI selection. Source: Taburalized by Author

\begin{tabular}{lllll}
\hline No & Nation & No. of HEI & Viva mode & Respondent profile \\
\hline 1 & Bahrain & 1 & Face-to-Face & Students \\
2 & Botswana & 1 & Face-to-Face & Students \\
3 & Canada & 1 & Virtual & Coordinators \\
4 & Germany & 1 & Virtual & Coordinators \\
5 & Ghana & 1 & Face-to-Face & Coordinators \\
6 & India & 1 & Face-to-Face & Coordinators \\
7 & Indonesia & 1 & Yet to Decide & Coordinators \\
8 & Malaysia & 1 & Virtual & Coordinators \\
9 & Palestine & 1 & Yet to Decide & Coordinators \\
10 & Serbia & 1 & Face-to-Face & Students \\
11 & Singapore & 1 & Virtual & Coordinators \\
12 & United Kingdom & 1 & Virtual & Students \\
13 & United States of America & 1 & Virtual & Students \\
\hline
\end{tabular}

extreme-homogeneity in sampling will also lead to biased findings. For this purpose, the respondents were chosen inherently from thirteen different countries. However, ultimately, they were still representing from higher education institutions (HEIs), so the homogeneity factor was evident. From these 13 HEIs around 56 samples were considered for this study-based sample calculation.
Journey of research was tedious as collecting data from thirteen different HEIs located in multiple nations during Covid-19 pandemic period was challenging. With the support of leaders in each research department, this was made possible. During focus-group sessions, respondents were invited virtually to share their views about virtual defense. Six institutions discussed its merit on flexibility; 
Table 3 Correlation between variables. Source: Data Analysis outcome

\begin{tabular}{|c|c|c|c|c|c|c|c|}
\hline \multicolumn{8}{|l|}{ Correlations } \\
\hline & & Technology & $\begin{array}{c}\text { Assessment } \\
\text { rubrics }\end{array}$ & $\begin{array}{l}\text { Interpersonal } \\
\text { skills }\end{array}$ & $\begin{array}{l}\text { Research } \\
\text { defense }\end{array}$ & $\begin{array}{l}\text { Online } \\
\text { platforms }\end{array}$ & $\begin{array}{l}\text { Virtual } \\
\text { defense }\end{array}$ \\
\hline \multirow[t]{3}{*}{ Technology } & $\begin{array}{l}\text { Pearson } \\
\quad \text { correlation }\end{array}$ & 1 & .037 & .164 & -.035 & .175 & .079 \\
\hline & Sig. (2-tailed) & & .789 & .229 & .798 & .197 & .564 \\
\hline & $\mathrm{N}$ & 56 & 56 & 56 & 56 & 56 & 56 \\
\hline \multirow[t]{3}{*}{$\begin{array}{l}\text { Assessment } \\
\text { rubrics }\end{array}$} & $\begin{array}{l}\text { Pearson } \\
\quad \text { correlation }\end{array}$ & .037 & 1 & .129 & .017 & $.296^{*}$ & -.095 \\
\hline & Sig. (2-tailed) & .789 & & .345 & .903 & .027 & .485 \\
\hline & $\mathrm{N}$ & 56 & 56 & 56 & 56 & 56 & 56 \\
\hline \multirow[t]{3}{*}{$\begin{array}{l}\text { Interpersonal } \\
\text { skills }\end{array}$} & $\begin{array}{l}\text { Pearson } \\
\quad \text { correlation }\end{array}$ & .164 & .129 & 1 & .114 & -.056 & .120 \\
\hline & Sig. (2-tailed) & .229 & .345 & & .403 & .680 & .379 \\
\hline & $\mathrm{N}$ & 56 & 56 & 56 & 56 & 56 & 56 \\
\hline \multirow[t]{3}{*}{ Research_Defense } & $\begin{array}{l}\text { Pearson } \\
\quad \text { correlation }\end{array}$ & -.035 & .017 & .114 & 1 & -.008 & .119 \\
\hline & Sig. (2-tailed) & .798 & .903 & .403 & & .952 & .384 \\
\hline & $\mathrm{N}$ & 56 & 56 & 56 & 56 & 56 & 56 \\
\hline \multirow[t]{3}{*}{ Online_Platforms } & $\begin{array}{l}\text { Pearson } \\
\quad \text { correlation }\end{array}$ & .175 & $.296^{*}$ & -.056 & -.008 & 1 & -.050 \\
\hline & Sig. (2-tailed) & .197 & .027 & .680 & .952 & & .716 \\
\hline & $\mathrm{N}$ & 56 & 56 & 56 & 56 & 56 & 56 \\
\hline \multirow[t]{3}{*}{ Virtual_Defense } & $\begin{array}{l}\text { Pearson } \\
\quad \text { correlation }\end{array}$ & .079 & -.095 & .120 & .119 & -.050 & 1 \\
\hline & Sig. (2-tailed) & .564 & .485 & .379 & .384 & .716 & \\
\hline & $\mathrm{N}$ & 56 & 56 & 56 & 56 & 56 & 56 \\
\hline
\end{tabular}

*Correlation is significant at the 0.05 level (2-tailed)

however, it was not a free talk between all of them. Fear of identity and HEI names were hindering the respondents to reveal facts on behalf of their institution. Had it been on individual perception, there could have been a probability to get more candid views. This led author to undergo another traditional survey with questionnaire as research instrument. Ultimately, Delphi technique became appropriate. The rationale behind this sample size calculation is as follows.

\section{Rationale for Sample Size}

56 respondents from thirteen Universities were considered for this research. These are based on judgmental sampling because author has to consider only HEIs those are conducting viva defense on regular basis. The scale for data collection is based on willingness or readiness to use virtual defense by universities. Hence, out of several universities, only those were flagging to get virtual defense was considered. This is why thirteen institutions were considered. In academic research, it is understood that judgmental and convenience sampling have to be avoided, but for this study, it is well known that the respondents have to have a grip on virtual defense or at least with doctoral defense practices. Thus, for certain researches, in education judgmental sampling can be used (Alrifai \& Raju, 2019). In doctoral defense, the oral examination is the final assessment. This is called as viva voce. This viva voce is conducted in last tenure of doctoral program. The institutions may schedule viva for one candidate between two hours to four hours. This is a general practice. This viva is conducted regularly based on compliance of students and availability of external examiners. Few Universities conduct viva periodically due to low volume of $\mathrm{PhD}$ candidature. Thus, it was screened judgmentally of those Universities which conduct viva regularly and to know, how is the process of viva now in post-pandemic days? Due to research ethics and confidentiality purpose, the names of Universities are kept hidden; however, the native of these Universities is from the following nations. Five respondents were chosen from each University are 
categorized under coordinator and candidate. With total of 5 respondents from each 13 Universities, the target population is 65 respondents. The sample size was calculated using below formula,

$X=Z\left(\frac{c}{100}\right) 2 r(100-r)$

$\mathrm{n}=\mathrm{N} \frac{\mathrm{x}}{(\mathrm{N}-1) \mathrm{E} 2+\mathrm{x}}$

$E=\iint\left[\frac{(N-n) x}{n(N-1)}\right]$

In above, the term ' $\mathrm{N}$ ' represents target population, whereas ' $r$ ' represents the portion of responses which was collected and finally ' $\mathrm{Z}(\mathrm{c} / 100)$ ' stands as critical-value toward the confidence level which is represented by 'c.' The same has been keyed in Raosoft sample size calculator and following has been derived with the margin of error $5 \%$ and $95 \%$ of confidence level. Thus, the sample size is 56.

Apart from above calculation, the same has been derived from Raosoft calculator. This is predominantly used for calculating sample size when the population (unit analysis) is small in numbers. In this research, there were only 13 institutions as population. From these HEIs, the author has picked the respondents through above calculation and with Raosoft.

\section{Sample Institutions}

The following nations were not by choice, but after mapping, the headquarters of respective HEIs these nations were made as target. It is to be noted that the purpose of this research is neither to study about HEI nor about target nations, it is purely on notion of process of virtual system implementation in HEI's viva conduction. Thus, the focus remains on process.

\section{Results and Findings}

Responses from 56 participants were evaluated through SmartPLS 3.2.8 (Ringle et al., 2015). A detailed analysis on descriptive statistics, correlation, regression, reliability, ANOVA was performed to identify the comfort level of using virtual system, i.e., online presentation in viva voce. Out of 56 respondents, 33 were male and 23 were female. Though this does not have impact on this research, it has to be understood that mean of viva mode from men was more compared to female's face-to-face mode.

\section{General Linear Model (Table 4)}

Non-linear relationship is not done in this research because the change in either of variables, i.e., technology. Assessment rubrics. International personal skills will not affect the virtual defense. These both entities, i.e., constructs are important for arriving the dependent variable. Hence, nonlinear relationships were avoided.

Table 4 Between-subjects factors

\begin{tabular}{llll}
\hline & & Value label & $\mathrm{N}$ \\
\hline Technology & 3 & Neutral & 6 \\
& 4 & Agree & 13 \\
& 5 & Strongly & 37 \\
Assessment & & agree & \\
rubrics & 3 & Neutral & 6 \\
& & & \\
& 4 & Agree & 15 \\
Interpersonal & 5 & Strongly & 35 \\
skills & 5 & agree & \\
& 3 & Neutral & 7 \\
& & Agree & 12 \\
Research defense & 4 & Strongly & 37 \\
& 5 & agree & \\
& 3 & Neutral & 4 \\
& 4 & Agree & 14 \\
& 5 & Strongly & 38 \\
& & agree & \\
\hline
\end{tabular}

\section{Outcome-based interpretation-Descriptive} statistics (Tables 5 and 6)

Table 5 Descriptive Statistics

\begin{tabular}{llllrl}
\hline & N & Minimum & Maximum & Mean & SD \\
\hline Gender & 56 & 1 & 2 & 1.29 & 0.456 \\
Age & 56 & 23 & 36 & 27.45 & 3.057 \\
Viva mode & 56 & 1 & 2 & 1.82 & 0.386 \\
Valid N (listwise) & 56 & & & & \\
\hline
\end{tabular}

Key: Gender 1 = Male, $2=$ Female; Viva Mode $1=$ Virtual, $2=$ Faceto-Face

Table 6 Reliability statistics

\begin{tabular}{ll}
\hline Cronbach's Alpha & N of Items \\
\hline 0.737 & 2 \\
\hline
\end{tabular}


Fig. 4 Proposed model for developing rubrics

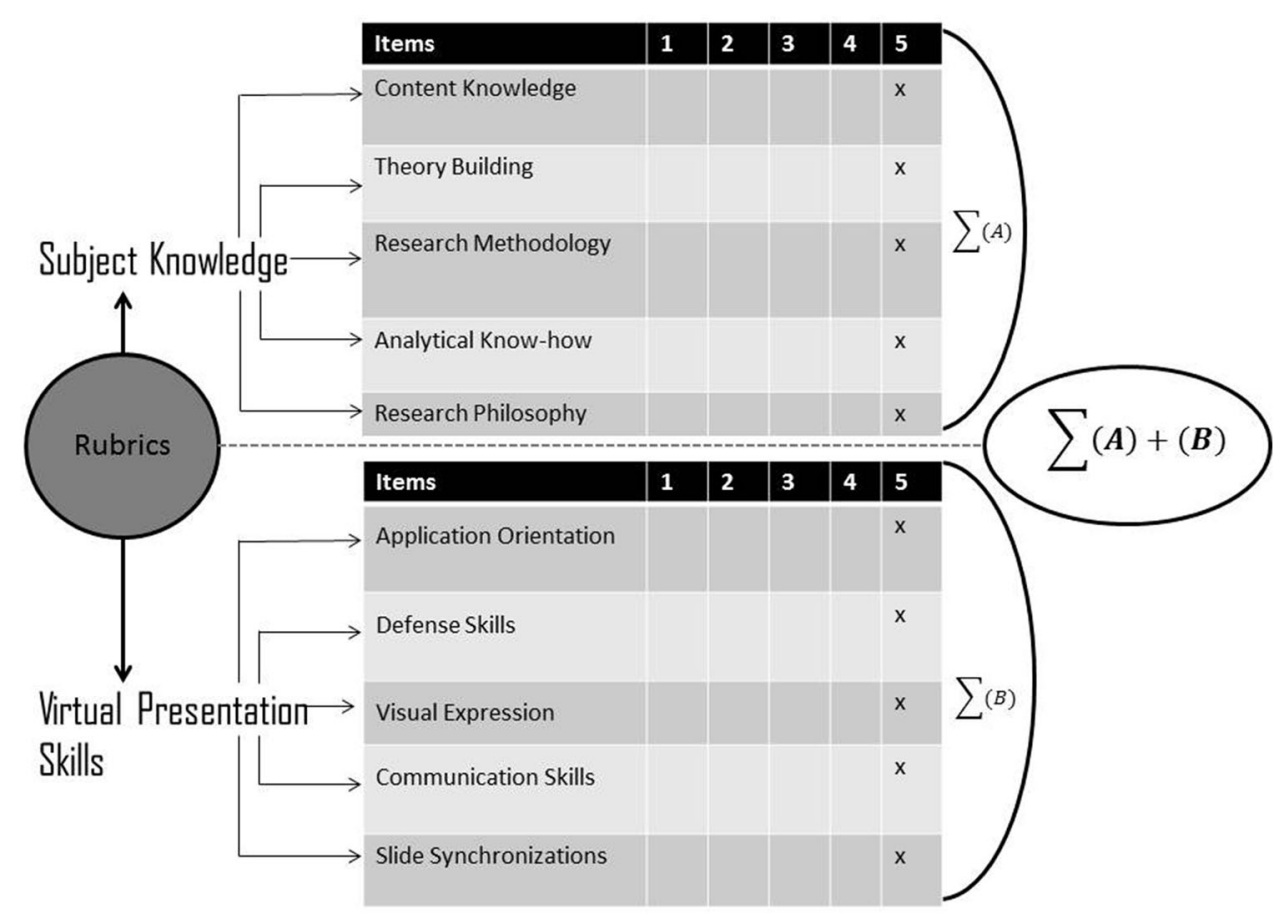

\section{Reliability}

According to (Hair, 2006), the overall reliability being above 0.6 or higher as a rule of thumb proves the constructs are being reliable with adequate sequence. This analysis indicates the fact that a level should prominently reflect the variable. In general, the researchers perform reliability analysis when two different observations under one study are equivalent to each other with regard to the variable which is being measured may have the similar output.

It is to be noted that $P$ value has to be lesser than 0.05 . In this research, it is evident that this is significant and Cronbach alpha is above 0.6. The results are proven to be significant through these testing.

\section{Developing Rubrics}

It was understood from the literature review that most of rubric formats that are used are for face-to-face viva defense, i.e., non-virtual defense. Based on the research, it was identified the need to develop dedicated rubrics for virtual defenses. The independent variables such as technology, assessment rubrics, interpersonal skills and research defense are key factors that influence virtual defense (Pinsky et al., 2020). Among this, the assessment rubrics have been tested with the mediator of online platforms. This is due to the fact that virtual defenses cannot be assessed without certain exclusive rubrics format. For this purpose, a dedicated rubric has been developed based on research outcome from respondents. In following Fig. 4, two main classifications are drawn. Subject knowledge and virtual presentation skills are derived from research that has been conducted for this study. Here, subject knowledge reflects the candidate's caliber on research thesis. This is the foremost concern. The existing rubrics are built to assess this section alone. Hence, the author does not claim a new contribution in this part, whereas in virtual presentation skills are the new addition or novelty of this research. There needs to be different assessment metrics when it comes to virtual defense, thus this part is entirely unique among the existing rubrics (Sushil, 2016). Application orientation, defense skills, visual expression, communication skills and slide synchronizations are the valueaddition for the assessment metrics.

Below Fig. 4 is the proposed model for developing rubrics for virtual defense.

Application orientation is about the user-friendliness of the application to the candidate. There are multiple platforms such as Zoom, Google Meet, Microsoft Teams, Padlet, and Moodle which are used for virtual defense. It was found that majority of research presentations are done through Microsoft Teams, merely due to its built-in package of Microsoft Windows. It is important for the candidate to get oriented with particular platform. While defending in face-to-face, there are only general body gestures to be monitored. But while presenting virtually, there needs to be a care on knowing the technology primarily, that is, the application. Defense skills are about the defending attitude 
in virtual environment. Usually in face-to-face scenario, there can be quality-defense by the candidate. While presenting virtually, this is difficult. Technological setbacks such as audibility factor, internet speed, time-lapse cause a barricade or distracts the candidate to core. Due to this, there may be a weak defense summarized by candidate. Mere practice alone can wipe this stain. There are speculations that sometimes defense may end up in argument, which will make the entire viva voce in to a mess(Waqar Younas* et al., 2019). This is neither a pro or con for this kind of mode, but care has to be taken to improve defense skills in virtual viva voce. Visual expression is a replacement of eye-contact that is done at face-to-face viva. In virtual meet, there is no possibility of eye-contact. And if the presentation goes beyond a timeline, the crux of defense is lost. Thus, a flexibility is predominantly important in academic ecosystem (Sushil, 2016). It is suggested to have visual expression, that is, a close observation on other ends without distractions. Having visual expression enables the candidate to win the psychological aspect from the panel. Next is on communication a skill which is common to both face-to-face viva and virtual viva. However, the distinction arises on empathy. That is, "whether the opponent person understood what I said?' either panel or candidates are not in a position to compromise this. Lastly, the slide synchronization is about how the candidate has grip on his or her presentation slides. It is the duty of candidate to drive the entire panel. Corresponding slides are to be kept at display when it is been explained.

If the synchronization is missed, the gap extends between candidate and panel (Hair Jr et al., 2017). This issue is usually sorted spontaneously in face-to-face scenario. But while doing a virtual presentation, these concerns have to be taken care. Thus, the candidate has to synchronize the presentation slides along with his or her communication.

\section{Discussion: Resilient Virtual System with Flexibility}

Through this research, it is clear and evident that practice of virtual defense could be in place if well executed. Virtual systems are those technological innovation built to bridge the gap in geography. In simple terms, these are kind of computers or applications which enable users to get connected remotely. The industrial revolution 4.0 has been phenomenal in terms of intelligent findings to ease the business, production, trade and economy. One such thing is virtual system. It is commonly called as virtual machine. There are multiple benefits of virtual system (Raju, 2019). Off late in education section, this virtual system has intruded with bigger motive (Ackroyd et al., 1989). Keeping aside all negative effects, if the crux is seen in detail, then one can understand its potential. Always challenges offer new opportunities. After conducting this research with academia, the need of resilient virtual system is evident. Based on respondents' outcome, following are submitted as suggestions for tech savvies to develop a prominent virtual system.

- Developing an application to access multiple-computers through one central unit console

- Availing built-in plugin of augmented reality thus it serves as enhanced virtual system

- Uninterrupted signal loadings by application for uninterrupted broadcast

- Building user-friendly visual and utility interface

- Interface with concave zoom-options thus 360 degree of physical environment is visible

- Ability to track the performance of presenter's interpersonal skills and facial recognition

- Building ChatBot with artificial intelligence to make system to synchronize with presentation slides

- Automated fixing of operating system functions without interrupting the viva defense

- Improvised application stability

- Encrypted system to avoid discrepancies

\section{(+) All above along with existing features in Virtual} Machines.

Virtual systems are those which enables the users to access multiple systems (computers, IT gadgets) through a universal console. The proposed model is built upon the philosophy of connecting dual or more systems for a viva defense purpose. If there are certain additional features plugged-in, then this becomes a supplement in educational assessment of candidates. Hence the above model portrays virtual presentation skills which can have augmented reality as one among the element. This will give both the panel and the presenter a real-life feel or could be to the extent of tangibility factor. Platforms like Zoom, WebEx, Google Meet, Adobe Connect, etc., can be used and installed with an additional plugin for this augmented reality. Along with this, if there is a ChatBot added to the streaming, then this is still more efficient because this kind of artificial intelligence can add value in virtual systems (Alkipsy et al., 2020). For instance, during the presentation, there can be lack of integrity from the candidate who may plagiarize the presentation dramatically in front of panel. This can be duly noted if there is a ChatBot which can perform facial recognition and voice mapping (Raju and Phung, 2019). This allows the panel to delegate the vetting of integrity to the systems. This innovative process may sound cumbersome, but this is possible. These are already in existence as stand-alone concept. It is proposed to 
integrate these with virtual systems so that it adds value to the entire mechanism.

One prominent setback that will be questioned in this model is, if there is failure in systems or interruptions in operating system how this can be encountered? To overcome this issue, it is also proposed to create a self-backup system and automated fixing technology in these platforms as plugins. By this all data, presentation, video, recordings, discussions that were held during the defense will be backed-up in cloud and at same time a recovery module will fix the issue caused by the operating system. The latter is not in existence so far, and hence, it could be a big ask through this model. However, it is proposed herewith humbly for future tech-savvy geeks to find a solution. Lastly, to avoid any ambiguities in theft or misuse of data, it is advised to encrypt the entire proceedings. Recent claim that Zoom platform is unsafe is due to the fact that it is not encrypted (Dastisheh \& Raju, 2020). Their paid-versions are encrypted. Thus, all virtual system that is brought to market should have the encryption so that it is secured to use. A viva defense is an important presentation, whereby many recommendations and outcomes are discussed (Raju $\&$ Phung, 2019). If these are leaked out in social media without the permission of author or institution, then it will create havoc in society. Thus, encryption is must. Overall, these new plugins improve the application stability.

The above model is been justified with additional inputs from experts in research and academia. Though these are not included here in discussion, it shall be used for future research publications. However, the present proposed model itself is highly sufficient to solve the crisis of virtual systems that are highlighted by experts.

Reason for using these particular nations was purely due to the merits of research that each respective nation has obtained. While it could be a limitation for this research to use only $1.5 \%$ of total nations in world, however, this research is not industry-specific, it is practice-specific. Hence considering limited number of nations, will lead to healthier findings, was the assumption that was taken. Research is to narrate lot about little. As future scope of this research, it would be encouraged to study different nation's perspectives.

\section{Recommendations}

While there are ample of opinions from respondents to submit as recommendation, after a meticulous filtering the following suggestions were re-brainstormed with similar group of people and arrived herewith. Thus, these recommendations are not from author or any single individual or studies. These are analyzed outcome from research as whole.
To implement customized rubrics to examine virtual defenses in higher education. Through this research an exclusive rubrics-development scheme has been submitted. However, this is not a complete assessment method. It is a methodology.

To develop resilient virtual application that enables convenient and secured virtual defenses. Present mechanisms are not just obsolete, but weak in terms of connectivity, compatibility and security. A defense for Viva should be secured, because it is a submission of multiple recommendations.

Apart from above recommendation, it is also to be noted that certain key aspects like leadership, adaptability, infrastructure requirements, etc., are to be dealt with in institutional policies. It would make less sense to organize virtual defense without infrastructural support. However, these recommendations are not from this particular research these are found while reviewing studies. It is been attempted to gather these points and expressed as 'recommendation.'

By implementing virtual mechanism in doctoral viva defense, the importance of flexible systems will be captured by the takers, i.e., the students and recipients of these merits. It is recommended through this research that if an institution is unwilling to conduct virtual defense, then there can be a dual mode of mechanism, i.e., to have faceto-face defense and at same time have virtual mode for assessing. Either of examiners may not be present in viva defense, for them virtual system can abet the process. However, these all are to bring to flexibility in systems without compromising the quality of viva defense. This recommendation can be called as 'mixed mode defense.' This research manuscript emphases this practice so that there can be a smoother transition from traditional practice to virtual practice.

\section{Conclusion}

'The cumulative sum of subject knowledge and virtual presentation skills can enable the practice of virtual defenses to be successful' - this moral is been derived from the research. These 56 homogenous samples were intersecting on one constructive point, i.e., to align the rubrics with virtual assessment. Thus, after consolidating the analysis, above Fig. 4 was constructed by author. As addressed in 'evidence of problem' section, if these kinds of measurement schemes are not brought in then this entire online-viva mechanism would be flawed periodically. Any inductive research is welcomed to counter this model, so that the need stays active. There could be a better model or system than the proposed model, whereas this research 
paper can distinct itself by claiming that this is the foremost proposal for this kind of problem.

This oral examination through online is called as virtual defense. The present system for virtual defenses is weak. Hence, there is a need to develop an austere resilience virtual system to conduct virtual defenses. This research is done with the scope of proposing a model to develop new methods for Ph.D. assessment rubrics, to develop resilient virtual system and certain recommendations are suggested based on data gathered from the respondents.

Developing a virtual application is apparently the need of the hour, for researchers to grow further and to contribute further. The ideology of conventional educational practices is getting limited due to Covid-19 because many candidates have not stepped into their campus. Few Governments across the world have announced that potgraduate students are permitted to visit their campuses, however, certain borders still remain closed. In this situation, the HEI has to take measures to conduct the final examination, oral examination, assessments through online, i.e., virtually (Dastisheh \& Raju, 2020).

From this research, it is understood that virtual defense practice is healthy for doctoral viva voce if followed by proper rubrics. Through this research the aforementioned 'rubrics' are also derived and mentioned with pictorial representation.

\section{Declarations}

Conflict of interest This research manuscript is drafted as outcome of research that is executed solely from the author and it has been neither sourced nor published elsewhere.

\section{References}

Abbott, A., \& Banerji, K. (2003). Strategic flexibility and firm performance: the case of US based transnational corporations. Global Journal of Flexible Systems Management, 4(1/2), 1-7.

Acharya, S. (2019). Beyond learning outcomes: Impact of organizational flexibility on strategic performance measures of commercial e-learning providers. Global Journal of Flexible Systems Management, 20(1), 31-41.

Ackroyd, S., Hughes, J. A., \& Soothill, K. (1989). Public sector services and their management. Journal of Management Studies. https://doi.org/10.1111/j.1467-6486.1989.tb00747.x

Agrawal, U., Mangla, A., \& Sagar, M. (2016). Company-causecustomer: Interaction architecture. Global Journal of Flexible Systems Management, 17(3), 307-319. https://doi.org/10.1007/ s40171-016-0128-2

Alexandra, T., \& Gordon, S. (2020, March 20). Delphi method definition. Investopedia. https://www.investopedia.com/terms/d/ delphi-method.asp

Alkipsy, E. I. H., Raju, V., \& Kumar, H. (2020). A review of the challenges of energy sector and prospects of renewable energy utilization in Yemen. Global Journal of Management and Business Research. https://doi.org/10.34257/gjmbravol20is8pg1
Alrifai, A. A., \& Raju, V. (2019). The employability skills of higher education graduates: A review of literature. IARJSET, 6(3), 83. https://doi.org/10.17148/iarjset.2019.6315

Bernoulli, D. (1954). Exposition of a new theory on the measurement of risk. Econometrica, 22, 23-36. https://doi.org/10.2307/190 9829

Bhaumik, A., Law, K. A., Jiemiao, F., \& Raju, V. (2019). Impact of globalization of firms: Descriptive study on performance on network ability. International Journal of Control and Automation, 12(5), 235-244. https://doi.org/10.33832/ijca.2019.12.5.01

Chetty, V. R. K., \& Phung, S. P. (2018). Economics behind education: Elements of development outcomes through political involvement. Eurasian Journal of Analytical Chemistry, 13(6), 146-157. http://www.eurasianjournals.com/Economics-BehindEducation-Elements-of-Development-Outcomes-through-PoliticalInvolvement, 104468,0,2.html

Dastisheh, A., \& Raju, V. (2020). Impact of Covid-19 on sponsorship marketing. Global Journal of Emerging Sciences. https://doi.org/ 10.37187/gjoes.0320.0201.03

Evans, S., \& Bahrami, H. (2020). Super-flexibility in practice: Insights from a crisis. Global Journal of Flexible Systems Management, 21(3), 207-214.

Farooq, M., \& Raju, V. (2019). Impact of Over-the-Top (OTT) services on the telecom companies in the era of transformative marketing. Global Journal of Flexible Systems Management, 20(2), 178-188. https://doi.org/10.1007/s40171-019-00209-6

Grover, P., \& Kar, A. K. (2017). Big data analytics: A review on theoretical contributions and tools used in literature. Global Journal of Flexible Systems Management. https://doi.org/ 10.1007/s40171-017-0159-3

Hair, J. F. (2006). Successful Strategies for Teaching Multivariate Statistics. Proceedings of the 7th International Conference on..., $1-5$.

Hair, J. F., Jr., Hult, G. T. M., Ringle, C., \& Sarstedt, M. (2017). A primer on partial least squares structural equation modeling (PLS-SEM). Sage Publications.

Hanafizadeh, P., \& Nik, M. R. H. (2020). Configuration of data monetization: A review of literature with thematic analysis. Global Journal of Flexible Systems Management, 21(1), 17-34.

Harvard Business Review. (2016). Five critical roles in project management. Harvard Business Review. https://hbr.org/2016/11/five-critical-roles-in-projectmanagement

Hmedan, M., Chetty, V. R. K., \& Phung, S. P. (2018). Malaysian tourism sector: Technical review on policies and regulations. Eurasian Journal of Analytical Chemistry, 13(6), 114-120. emSJAC181129.

Hwang, G.-J., Sung, H.-Y., Chang, S.-C., \& Huang, X.-C. (2020). A fuzzy expert system-based adaptive learning approach to improving students' learning performances by considering affective and cognitive factors. Computers and Education: Artificial Intelligence, 1, 100003. https://doi.org/10.1016/j.caeai. 2020.100003

Hu, P. J., Chau, P. Y. K., Sheng, O. R. L. \& Tam, K. Y. , \& To. (2016). Journal of management information systems. Journal of Management Information Systems ISSN, 16(2), 91-112. https:// doi.org/10.1080/07421222.1999.11518247

Kolt, G. S. (2009). Practical applications of research findings. Journal of Science and Medicine in Sport, 12, 251. https://doi.org/ 10.1016/j.jsams.2009.02.001

Law, K. A., Bhaumik, A., Fang, J., \& Raju, V. (2020). Exploring network capability, international opportunity recognition and development on the international performance of born global firms in China. Test Engineering and Management, 83. 
O'Connor, J. (2004). Book reviews. European Urban and Regional Studies, 11(1), 92-93. https://doi.org/10.1177/09697764041 11009

Piansoongnern, O. (2013). Flexible leadership for managing talented employees in the securities industry: A case study of Thailand. Global Journal of Flexible Systems Management, 14(2), 107. https://doi.org/10.1007/s40171-013-0036-7

Pinsky, V., Kruglianskas, I., \& Gomes, C. M. (2020). Conducting research in climate finance in Latin America: Challenges and opportunities of using grounded theory methodology approach. Global Journal of Flexible Systems Management. https://doi.org/ 10.1007/s40171-020-00241-x

Poh Phung, S., Valliappan Raju, A., \& Nazeh, M. (2019). integrated study on reviewing decision making process and management information system. In International Journal of Engineering and Technology (Vol. 8, Issue 1). www.sciencepubco.com/index. $\mathrm{php} / \mathrm{IJET}$

Popescu, V. G., Burdea, G. C., Bouzit, M., \& Hentz, V. R. (2000). A virtual-reality-based telerehabilitation system with force feedback. IEEE Transactions on Information Technology in Biomedicine. https://doi.org/10.1109/4233.826858

Raju, V. (2019). Vally theory of motivation-by-disguise. Test Engineering and Management, 81(10), 1910-1913. https://www. scopus.com/record/display.uri?eid=2-s2.0-85084414526\&origin =inward\&txGid=2e5f95b2e84f 40b231a823a2036a2eba\#

Raju, V., \& Phung, S. P. (2019). Role of Blockchain using Distributed Ledger Technology (DLT) in security exchange commissions. Test Engineering and Management, 81.

Raju, V., \& Phung, S. P. (2020). Economic dimensions of blockchain technology: In the context of extention of cryptocurrencies. International Journal of Psychosocial Rehabilitation, 24(2), 29-39. https://doi.org/10.37200/IJPR/V24I2/PR200307

Raju, V., \& Tamjis, M. R. (2018). Production of Methane Gas from Cow's Residue: Biogas as Alternative Energy in Transportation and Electricity. Eurasian Journal of Analytical Chemistry, 13(6), 121-124.

Rao, K. S., \& Wadhwa, S. (2002). Global journal of flexible systems management giftjourn @ 1 Editorial. Global Journal of Flexible Systems Management.

Ringle, C., Wende, S., \& Becker, J. (2015). Ringle, Christian M., Wende, Sven, \& Becker, Jan-Michael. (2015). SmartPLS 3. Bönningstedt: SmartPLS. Retrieved from http://www.smartpls. com. In Retrieved from.

Sharma, M. K., Sushil, \& Jain, P. K. (2010). Revisiting flexibility in organizations: Exploring its impact on performance. Global Journal of Flexible Systems Management, 11, 51-68. https://doi.org/10.1007/BF03396587

Shukla, S. K., Sushil, \& Sharma, M. K. (2019). Managerial paradox toward flexibility: Emergent views using thematic analysis of literature. Global Journal of Flexible Systems Management, 20(4), 349-370.
Simpson, R. (1983). How the PhD came to Britain: A century of struggle for postgraduate education. Open University Press, June, ISBN 978-0-900868-95-5. https://en.wikipedia.org/wiki/ Doctor_of_Philosophy

Sushil (1997). Flexible systems management- An evolving paradigm. Systems Research and Behavioral Science, 14(4), 259-275.

Sushil (2015). Strategic flexibility: The evolving paradigm of strategic management. Global Journal of Flexible Systems Management, 16(2), 247-248.

Sushil (2016). Strategic flexibility in ecosystem. Global Journal of Flexible Systems Management, 17(3), 247-248. https://doi.org/ 10.1007/s40171-016-0138-0

Wagner, J. (2001). International economics: Theory and policy, Global Edition. European Economic Review, 45(2). https://doi. org/10.1017/CBO9781107415324.004

Waqar Younas*, Mohammed, F., Khalil, F., \& Raju, V., (2019). Impact of self-control, financial literacy and financial behavior on financial well-being. The Journal of Social Sciences Research, 5(5), 211-218. https://doi.org/10.32861/jssr. 51.211.218.

Publisher's Note Springer Nature remains neutral with regard to jurisdictional claims in published maps and institutional affiliations.

\section{Key Questions}

1. What is the relevance of virtual system in present (21st century) economy?

2. How does flexibility mechanism will help SDG (Sustainable Developmental Goal)?

3. Can virtual systems replace traditional practice of oraldefense?

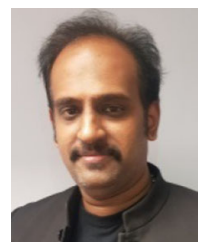

Valliappan Raju Assoc. Prof. Dr. Valliappan Raju is currently teaching at Post Graduate Centre in Limkokwing University, Malaysia. He specializes in teaching Research Methodology to doctoral researchers. He is appointed as an External Examiner for assessing Ph.D. viva voce at the Malaysian Public Universities. Over the years, many researchers have obtained their Ph.D. under his supervision. He has published more than $250+$ manuscripts, among them numerous are indexed in Scopus as him being the principal author. He actively reviews SCOPUS / ISI / WoS journals and World Bank Conference journals, USA. 